\title{
Endodontic Re-treatment of a Tooth with a Floor Perforation in a Patient in Treatment with Oral Bisphosphonate
}

Mario Dioguardi ${ }^{1}$, Giuseppe Troiano ${ }^{1 *}$, Giorgia Apollonia Caloro ${ }^{2}$, Armando Cocco ${ }^{1}$, Giorgia Capocasale ${ }^{3}$, Gianluca ladarola ${ }^{1}$ and Lorenzo Lo Muzio $^{1}$

${ }^{1}$ Department of Clinical and Experimental Medicine, University of Foggia, Italy

${ }^{2}$ Department of Emergency and Organ Transplantation - Nephrology, Dialysis and Transplantation Unit, University of Bari, Bari, Italy

${ }^{3}$ Department of Surgical, Oncological and Stomatological Disciplines, University of Palermo, Palermo, Italy

*Corresponding author: Dr. Giuseppe Troiano, Via Rovelli, 50, 71122 Foggia, Italy, Tel: +393488986409; E-mail: giuseppe.troiano@unifg.it

Received date: Apr 20, 2016; Accepted date: May 23, 2016; Published date: May 30, 2016

Copyright: ( 2016 Dioguardi M, et al. This is an open-access article distributed under the terms of the Creative Commons Attribution License, which permits unrestricted use, distribution, and reproduction in any medium, provided the original author and source are credited.

\begin{abstract}
Prevention of bisphosphonate related osteonecrosis of the jaws (BRONJ) represents an important challenge for clinicians. Dent alveolar surgery is usually performed to reduce the risk local and systemic complications, In fact, removing the tooth that is the source of the infectious outbreak, brings to the removal of the infected tissue and determines a correct healing of the disease. However, in patients are undergoing bisphosphonate this procedure expose patients to an increased risk of BRONJ. However, in patients who are in treatment with systemic bisphosphonates, this procedure exposes them to an increased risk of BRONJ. When possible, avoid the surgical interventions in favors of endodontic treatment could be an important clinical options in reducing the possibility of BRONJ occurrence. In this paper, we report a case of endodontic re-treatment in a tooth with a floor perforation in a patient was assuming oral alendronate. Limits and advantages of performing endodontic retreatment for the prevention of BRONJ development have still not well elucidated. Due to the very low power of this study, no conclusions should be made to perform an endodontic retreatment instead of performing a tooth extraction. However, this case report support the execution of future studies related to the calculation of BRONJ incidence after surgical extraction vs endodontic retreatment.
\end{abstract}

Keywords: Endodontic; Oral bisphosphonate; Oral medicine; Osteoporosis; Floor perforation

\section{Introduction}

The osteonecrosis of the jaws associated with bisphosphonate therapy (BRONJ) is a drug-related adverse event that may reduce the patient related quality of life [1]. The primary symptom of BRONJ is an exposure of necrotic bone in the oral cavity [2-4]. Bisphosphonates are a group of drugs used in the treatment of osteometabolic benign diseases, such as: osteoporosis [2], Paget's disease and others bone pathologies characterized by altered bone turnover and skeletal fragility [5,6]. They are also widely used in blood disorders (hypercalcemia) [3] and oncological pathologies [7,8]. In these last ones, they are used in order to prevent the arising of skeletal events, like bone metastases, especially in cancer of the: breast [9-11], prostate [4], renal [5] and in patients with multiple myeloma. On the basis of the disease severity, the bisphosphonate can be administered for oral, intramuscular or intravenous use [12-16]. One of the peculiarities of the osteonecrosis is the localization almost exclusively to the jaws' bone. Although, the possible causes of this phenomenon are unclear, a variety of factors are hypothesized, such as: high turnover bone of the jaws [17], characteristic anatomical terminal vascularization [6], fine mucoperiosteal layer over the hard tissues [7,18], and presence of a special microflora in the oral cavity $[8,19,20]$. Dental treatments may represent a possible cause for BRONJ occurrence. Dentoalveolar surgery is usually performed to reduce the risk local and systemic complications due to tooth infectious disease. In fact, remove the tooth that is the source of the infectious outbreak, brings to the removal of the infected tissue and determines a correct healing of the disease.
Although the dentoalveolar surgery is not contraindicated in absolute terms, it exposes the patient to the possibility of BRONJ onset [21]. Due to the persistence of infections of the jaws, avoid the surgical treatment, in some cases, increase the possibility of spontaneous BRONJ and, simultaneously, exposes the patient to the onset of infectious complications [9]. In such cases, the endodontic treatment of very compromised teeth, if predictable, is recommended in patients treated with bisphosphonates to avoid teeth extractions and get the healing of the intraosseous infections [10]. In fact, occurrence of osteonecrosis after endodontic therapy are very few and are probably related to procedural errors during the same treatment [11]. It is not clear, what is the best treatment option to prevent the development of BRONJ when teeth with incorrect endodontic treatment are present. The doubt lies in the choice of the clinician, is preferable to extract the tooth or perform endodontic retreatment. In patients who are not in treatment with biphosphonate, the most recent evidences of the literature militate in favor of conservative therapies in order to reduce as much as possible the extraction of teeth [12]. Nevertheless, in patients at risk of BRONJ development the potential and limits of the conservative therapies (as endodontic retreatment) have not been well elucidated, due to the possibility of treatment failure, which would expose patients to an increased risk of infections. In this paper, we report a very borderline case of a patient had taken oral Alendronate for ten years, who refused the extraction of a mandibular molar. At the radiographic evaluation, it was noticed the presence of a floor perforation and a broken instrument in the periodontium near the furcation that determined a reduction in the possibilities of success of the endodontic therapy. 
Citation: Dioguardi M, Troiano G, Caloro GA, Cocco A, Capocasale, et al. (2016) Endodontic Re-treatment of a Tooth with a Floor Perforation in a Patient in Treatment with Oral Bisphosphonate. J Gen Practice 4: 252. doi:10.4172/2329-9126.1000252

Page 2 of 4

\section{Case Presentation}

\section{Diagnosis and clinical history}

A 72 years-old-female was referred to our Department, concerning a continuous dull pain in the right side of the mandible, she also referred to have undergone an endodontic treatment of the tooth 4.6 seven months before. The tooth presented an adhesive class II restoration that bound elements 4.6 and 4.7. In addition, pain after percussion on the element 4.6 was revealed. Between distal and mesial root of 4.6 clinical attachments loss of $5 \mathrm{~mm}$ was recorded. At X-ray examination, signs of an incongruous endodontic therapy related to distal canal of 4.6 were revealed (Figure 1).

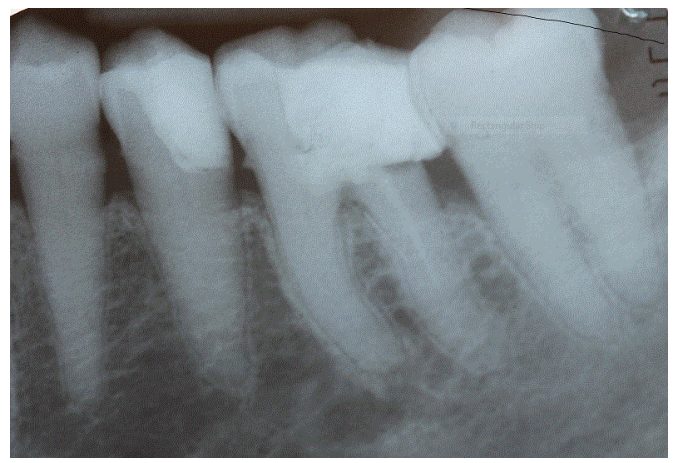

Figure 1: Pre-treatment periapical rx of the element 4.6.

Both mesial and distal channels were not appropriately shaped and sealed. A perforation of the floor chamber and a broken instrument were revealed in the adjacent periodontium. The patient declared to suffer of hypertensive disease; membranous glomerulonephritis stage IV and osteoporosis. Treatment of osteoporosis consisted of oral Alendronate and Vitamin D3, started 10 years before. On the basis of clinical and radiological examination, the diagnosis of apical periodontitis of the element 4.6 was made. The extraction of the element was proposed as recommended treatment, and the patient was informed to the possible risk of BRONJ development. However, the patient refused the extractive therapy, so we decided to perform an endodontic re-treatment informing the patient of the lower success rate of this therapy.

\section{Treatment modality}

The endodontic re-treatment was performed with the use of rubber dam, isolating only the element 4.6. The old canal obturation was removed with the use of a gutta-percha remover (GPR, Ogna Lab), and the use of NiTi manual instruments (ProTaper Universal, Dentsply Maillefer).

First shaping and closure of the canals were performed, than the floor perforation was treated with Mineral Trioxide Aggregate (MTA) paste (Auroseal; Ogna Pharma).

A composite restoration was performed after two weeks isolating the tooth with rubber dam, after that the absence of clinical disorders was noticed (Figure 2).

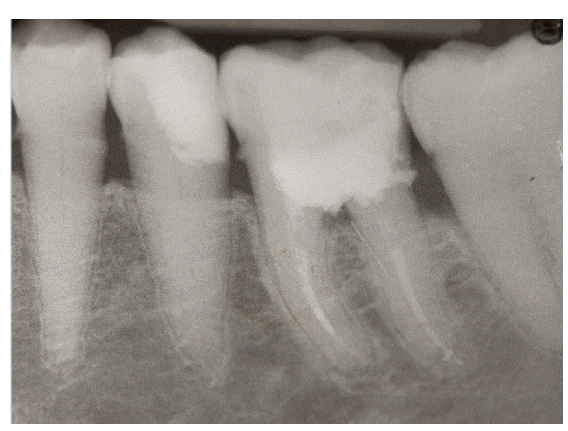

Figure 2: Post-treatment periapical rx showed a correct closure of the canals at the apex and the closure of the floor perforation.

The patient was discharged after the restorative treatment and recalled for follow-up every 6 months. At 2 year follow-up the absence of clinical disorders (absence of pain and inflammation), and healing of the furcation lesion was revealed both with periodontal surgery and $\mathrm{X}$-rays (Figures 3 and 4 ).

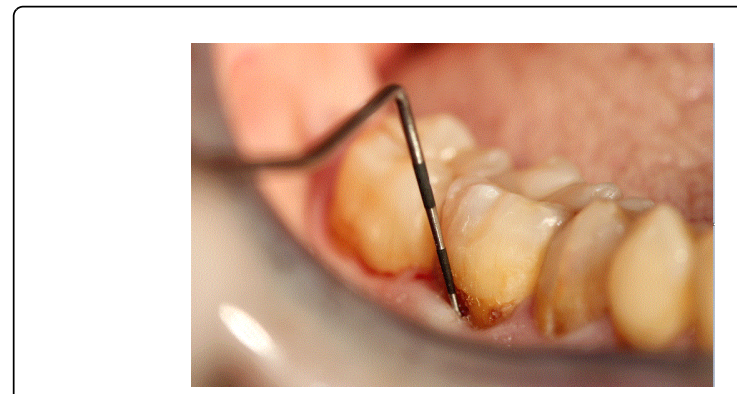

Figure 3: Vertical periodontal survey after 2 years follow-up revealed the healing of periodontal treatment.

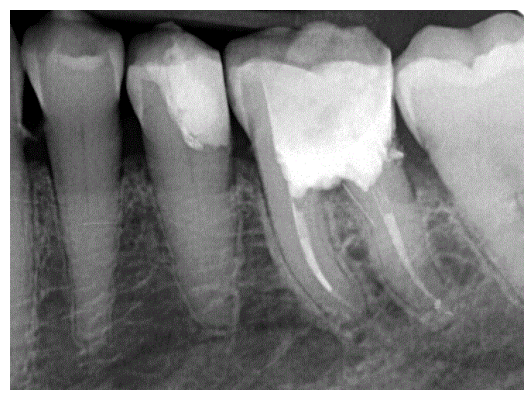

Figure 4: Periapical rx after 2 years follow-up revealed a stable situation of the element 4.6.

\section{Discussion}

Among dental procedures, those at a higher risk of BRONJ onset are tooth extraction and invasive surgical procedures [22-25], this risk has been confirmed by several studies [26-30]. Cases of BRONJ following endodontic treatment are described in literature, although in the majority of cases is associated with incorrect treatments. The aim of the endodontic treatment is to reach the cleaning and disinfection of 
the root canal system [31-33] in order to obtain an apical and coronal seal which acts as a barrier to the penetration of bacteria and toxins. These last ones are responsible of the inflammatory processes in the periodontal tissues and lead to BRONJ onset. Marx et al. [19] were the first to suppose the existence of association between endodontic therapy and BRONJ development. However, the association was related only to incorrect endodontic treatments. However, larger recent studies have failed to confirm an association between nonsurgical root canal therapy and BRONJ. Although, the quality of the evidence is low some authors recommended performing endodontic treatment in order to avoid dental extraction in patients receiving bisphosphonate [13]. To reduce the risk of development BRONJ the root canal therapy should be performed with all the necessary aids, in order to reduce the possibility of iatrogenic infection. For our experience, the use of rubber dam should be recommended despite some authors have supposed that the dam hook may represent a risk factor for the onset of BRONJ [6].

In this case the root canals re-treatment was choice as treatment modality following the patient's demands. This is a borderline case because the tooth presented a floor chamber perforation and a broken instrument in the periodontum adjacent to the furcation. However, a correct endodontic treatment may be successful also in patients undergoing biphosphonate as demonstrated in this case. In fact, the clinical absence of symptomatology and the radiographic appearance of periodontal healing demonstrated the success of the above mentioned treatment. The primary healing obtained with MTA treatment raises the likelihood of long-term success as demonstrated in a recent study [6]. The clinical and radiological (as revealed by disappearance of radio-transparency) healing of the furcation defect has revealed that the capacity for endodontic and periodontal regeneration is preserved in BRONJ patients. However, in some cases like this, failure of endodontic retreatment could lead to worsening bone infection and increase the probability of BRONJ development. Hence, a balancing between advantages and disadvantages should be performed before to choose the appropriate treatment option for these patients [34-37].

Due to the very low power of this study, no conclusions should be made to perform an endodontic retreatment instead of performing a tooth extraction. However, this case report support the execution of future studies related to the calculation of BRONJ incidence after surgical extraction vs. endodontic retreatment.

\section{Conclusion}

In this case we reported about a case of borderline endodontic treatment in a patient in treatment with oral alendronate. In such situations, to avoid the trauma of surgery, an endodontic re-treatment could be tried in order to reduce the possibility of developing biphosphonate related osteonecrosis of the jaws. However, due to the low power of this study no conclusions can be made about what is the best treatment choice in patients undergoing systemic bisphosphonate. However, this study encourages the performance of further studies that should evaluate what is the best treatment option to reduce the incidence of BRONJ.

\section{References}

1. Miksad RA, Lai KC, Dodson TB, Woo SB, Treister NS, et al. (2011) Quality of life implications of bisphosphonate-associated osteonecrosis of the jaw. Oncologist 16: 121-132.
2. Bagan JV, Jimenez Y, Hernandez S, Murillo J, Diaz JM, et al. (2009) Osteonecrosis of the jaws by intravenous bisphosphonates and osteoradionecrosis: a comparative study. Med Oral Patol Oral Cir Bucal 14: 616-619.

3. Bagan J, Crispian S, Vicente S, Yolanda J (2009) Osteonecrosis of the jaws in patients treated with intravenous bisphosphonates (BRONJ): A concise update. Oral Oncol 45: 551-554.

4. Cardona F, Bagan JV, Sainz E, Figuerido J, Giner F, et al. (2009) Bisphosphonate-related osteonecrosis of the jaws. An update. An Sist Sanit Navar 32: 413-421.

5. Kim DS, Kim JH, Ohe JY, Lee JW, Choi BJ, et al. (2015) Bisphosphonaterelated osteonecrosis of the jaw in a patient with osteoporosis following treatment of testicular cancer: a case report. J Korean Assoc Oral Maxillofac Surg 41: 327-331.

6. Polyzos SA, Anastasilakis AD, Makras P, Terpos E (2011) Paget's disease of bone and calcium homeostasis: focus on bisphosphonate treatment. Exp Clin Endocrinol Diabetes 119: 519-524.

7. Dawson C, Todd AM, Walton A (2014) Treatment of bisphosphonateresistant hypercalcemia of malignancy with calcitonin. J Palliat Med 17: 1084 .

8. Otto S, Schreyer C, Hafner S, Mast G, Ehrenfeld M, et al. (2012) Bisphosphonate-related osteonecrosis of the jaws - characteristics, risk factors, clinical features, localization and impact on oncological treatment. J Craniomaxillofac Surg 40: 303-309.

9. Varun B, Sivakumar T, Nair BJ, Joseph AP (2012) Bisphosphonate induced osteonecrosis of jaw in breast cancer patients: A systematic review. J Oral Maxillofac Pathol 16: 210-214.

9. Oura S, Hirai I, Yoshimasu T, Kokawa Y, Sasaki R, et al. (2003) Clinical efficacy of bisphosphonate therapy for bone metastasis from breast cancer. Breast Cancer 10: 28-32.

10. Aapro M, Monfardini S, Jirillo A, Basso U (2009) Management of primary and advanced breast cancer in older unfit patients (medical treatment). Cancer Treat Rev 35: 503-508.

11. Sallami S, Ben Rhouma S, Cherif K, Benrais N, Horchani A, et al. (2012) The role of bisphosphonate in the treatment of bone metastases from prostate cancer. Tunis Med 90: 507-511.

12. Harinck HI, Bijvoet OL, Plantingh AS, Body JJ, Elte JW, et al. (1987) Role of bone and kidney in tumor-induced hypercalcemia and its treatment with bisphosphonate and sodium chloride. Am J Med 82: 1133-1142.

13. Lawson MA, Ashcroft J, Croucher PI (2010) Bisphosphonate therapy in the treatment of multiple myeloma. Curr Pharm Des 16: 3028-3036.

14. Terpos E, Sezer O, Croucher PI, García-Sanz R, Boccadoro M (2009) The use of bisphosphonates in multiple myeloma: recommendations of an expert panel on behalf of the European Myeloma Network. Ann Oncol 20: 1303-1317.

15. Otto S, Troltzsch M, Jambrovic V, Panya S, Probst F, et al. (2015) Tooth extraction in patients receiving oral or intravenous bisphosphonate administration: A trigger for BRONJ development? J Craniomaxillofac Surg 43: 847-854.

16. Ruggiero SL, Dodson TB, Fantasia J, Goodday R, Aghaloo T, et al. (2014) American Association of Oral and Maxillofacial Surgeons position paper on medication-related osteonecrosis of the jaw--2014 update. J Oral Maxillofac Surg 72: 1938-1956.

17. Bagan JV, Murillo J, Jimenez Y, Poveda R, Milian MA, et al. (2005) Avascular jaw osteonecrosis in association with cancer chemotherapy: series of 10 cases. J Oral Pathol Med 34: 120-123.

18. Marx RE (2003) Pamidronate (Aredia) and zoledronate (Zometa) induced avascular necrosis of the jaws: a growing epidemic. J Oral Maxillofac Surg 61: 1115-1117.

19. Eckert AW, Maurer P, Meyer L, Kriwalsky MS, Rohrberg R, et al. (2007) Bisphosphonate-related jaw necrosis--severe complication in maxillofacial surgery. Cancer Treat Rev 33: 58-63.

20. Ruggiero SL, Mehrotra B, Rosenberg TJ, Engroff SL, et al. (2004) Osteonecrosis of the jaws associated with the use of bisphosphonates: a review of 63 cases. J Oral Maxillofac Surg 62: 527-534. 
Citation: Dioguardi M, Troiano G, Caloro GA, Cocco A, Capocasale, et al. (2016) Endodontic Re-treatment of a Tooth with a Floor Perforation in a Patient in Treatment with Oral Bisphosphonate. J Gen Practice 4: 252. doi:10.4172/2329-9126.1000252

Page 4 of 4

21. Campisi G, Compilato D, Angelo I, Lo Muzio L, Colella G, et al. (2012) Spontaneous bisphosphonate-related osteonecrosis of the left hemimandible: similarities with phossy jaw. Indian J Dent Res 2: 683-685.

22. Pemberton MN (2010) Osteonecrosis of the jaw. Note on dental procedures. BMJ.

23. Fugazzotto PA, Lightfoot S (2006) Bisphosphonate associated osteonecrosis of the jaws and endodontic treatment: two case reports. J Mass Dent Soc 55: 5.

24. Mavrokokki T, Cheng A, Stein B, Goss A (2007) Nature and frequency of bisphosphonate-associated osteonecrosis of the jaws in Australia. J Oral Maxillofac Surg 65: 415-423.

25. Pazianas M, Miller P, Blumentals WA, Bernal M, Kothawala P (2007) A review of the literature on osteonecrosis of the jaw in patients with osteoporosis treated with oral bisphosphonates: prevalence, risk factors, and clinical characteristics. Clin Ther 29: 1548-1558.

26. Hoff AO, Toth BB, Altundag K, Johnson MM, Warneke CL, et al. (2008) Frequency and risk factors associated with osteonecrosis of the jaw in cancer patients treated with intravenous bisphosphonates. J Bone Miner Res 23: 826-836.

27. Filleul OE, Crompot, Saussez S (2010) Bisphosphonate-induced osteonecrosis of the jaw: a review of 2,400 patient cases. J Cancer Res Clin Oncol 136: 1117-1124.

28. Katz H (2005) Endodontic implications of bisphosphonate-associated osteonecrosis of the jaws: a report of three cases. J Endod 31: 831-834.

29. Sarathy AP, Bourgeois SL, Goodell GG (2005) Bisphosphonate-associated osteonecrosis of the jaws and endodontic treatment: two case reports. J Endod 31: 759-763.
30. Huang D, Zhou X (2015) Diagnosis and treatment strategy of persistent endodontic diseases]. Zhonghua Kou Qiang Yi Xue Za Zhi 50: 325-330.

31. Rahimi S, Maryam J Mehrdad L, Shahriar S, Amirala A, et al. (2014) A review of antibacterial agents in endodontic treatment. Iran Endod J 9: 161-168.

32. Kyrgidis A, Arora A, Lyroudia K, Antoniades K (2010) Root canal therapy for the prevention of osteonecrosis of the jaws: an evidence based clinical update. Aust Endod J 36: 130-133.

33. Kyrgidis A, Vahtsevanos K, Koloutsos G, Andreadis C, Boukovinas I, et al. (2008) Bisphosphonate-related osteonecrosis of the jaws: a casecontrol study of risk factors in breast cancer patients. J Clin Oncol 26: 4634-4638.

34. Kyrgidis A, Triaridis S, Vahtsevanos K, Antoniades K (2009) Osteonecrosis of the jaw and bisphosphonate use in breast cancer patients. Expert Rev Anticancer Ther 9: 1125-1134.

35. Gallego L, Junquera L, Pelaz A, Diaz-Bobes C (2011) Rubber dam clamp trauma during endodontic treatment: a risk factor of bisphosphonaterelated osteonecrosis of the jaw? J Oral Maxillofac Surg 69: 93-95.

36. Gorni FG, Andreano A, Ambrogi F, Brambilla E, Gagliani M (2016) Patient and Clinical Characteristics Associated with Primary Healing of Iatrogenic Perforations after Root Canal Treatment: Results of a Longterm Italian Study. J Endod 42: 211-215. 